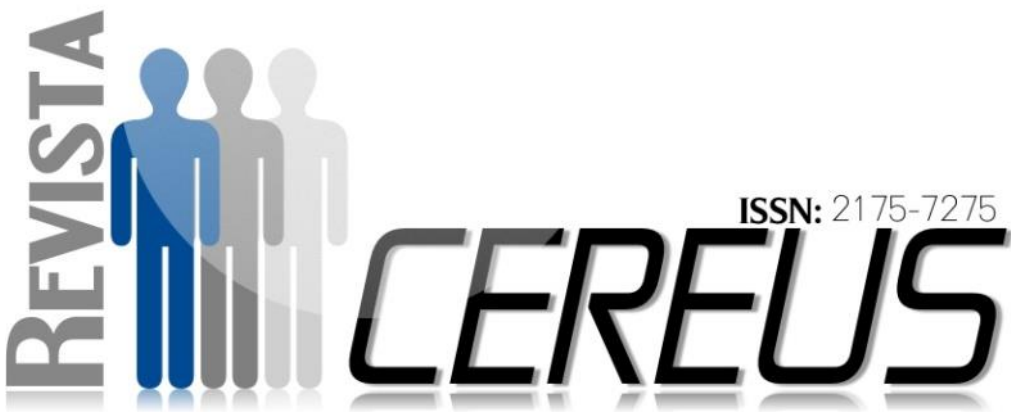

\section{OCORRÊNCIA DE FUNGOS QUERATINOFÍLICOS EM SOLO DE ÁREAS RECREACIONAIS DE SANTARÉM - PA, BRASIL}

\author{
VIDAL, Vânia Vieira ${ }^{1}$ \\ CANTO, Eveleise Samira Martins ${ }^{2}$ \\ SOUSA, Jael Saray Coelho de ${ }^{3}$ \\ FROTA, Jhessica Krhistinne Caetano ${ }^{4}$ \\ SANTOS, Taides Tavares dos ${ }^{5}$
}

\section{RESUMO}

Em ambientes recreacionais, seres humanos e animais de estimação convivem com alta proximidade. Dependendo das condições higiênico-sanitárias, fungos e outros microorganismos podem estar presentes nessas áreas e, potencialmente, provocarem infecções oportunistas. Diante disso, evidencia-se a importância de estudos sobre a ocorrência de fungos em áreas recreacionais. Neste contexto, o objetivo desse estudo foi verificar a presença de fungos filamentosos queratinofílicos em solos de parques e praças

1 Mestranda em Sociedade, Ambiente e Qualidade de Vida (PPGSAQ-UFOPA); Bacharel em Engenharia Sanitária e Ambiental (UFOPA)..

2 Licenciada em Biologia; Mestre em Ciências da Saúde; Doutoranda em Biodiversidade e Biotecnologia do PPG-BIONORTE. Professora de Microbiologia e Imunologia do Instituto de Ciências e Tecnologia das Águas (ICTA) da Universidade Federal do Oeste do Pará (UFOPA).

3 Discente do Bacharelado em Ciências Biológicas do Instituto de Ciências e Tecnologia das Águas (ICTA) da Universidade Federal do Oeste do Pará (UFOPA), Santarém, Pará, Brasil. 
públicas de Santarém, que é um dos municípios mais populosos do Estado do Pará. Para isso, análise microbiológica de amostras de solo para o isolamento de fungos foram realizadas, em diferentes períodos do ano, em seis ambientes utilizados como áreas de lazer pela população, sendo um parque e cinco praças. Entre os critérios de seleção dos ambientes amostrados, destacam-se o fluxo intenso de pessoas e de animais de estimação e a presença de resíduos orgânicos. Do total de 43 amostras analisadas, $81,4 \%$ foram positivas para as colônias fúngicas. A ocorrência dos grupos taxonômicos identificados do total de amostras positivas foram: Acremonium sp. (31,25\%), Paecilomyces sp. (20,83\%), Fusarium sp. (14,58\%), Penicillium sp. (8,33\%), Trichoderma sp. (4,14\%), Aspergillus sp. (2,08\%), Epidermophyton sp. (2,08\%), Rhizopus sp. (2,08\%), Sporothrix sp. (2,08\%), Trichophyton sp. (2,08\%). Concluiuse que no solo dos ambientes recreacionais estudados ocorrem tanto fungos dermatófitos como não dermatófitos, com potencial de provocarem infecções, indicando uma baixa qualidade higiênico-sanitária e potencial patogênico relevante do ponto de vista da saúde pública.

Palavras chave: Micoses. Dermatófitos. Qualidade do solo.

\section{OCCURRENCE OF QUERATINOFÍLIC FUNGES IN SOIL OF} RECREATIONAL AREAS OF SANTARÉM CITY, BRAZIL

\section{ABSTRACT}

In recreational environments, humans and pets live in close proximity. Depending on hygienic-sanitary conditions, fungi and other micro-organisms may be present in these areas and potentially lead to opportunistic infections. Therefore, the importance of studies on the occurrence of fungi in recreational areas is evidenced. In this context, the objective 
of this study was to verify the presence of queratinofílic filamentous fungi in soils of parks and public squares of Santarém city, which is one of the most populous municipalities in the Pará State. For this, microbiological analysis of soil samples for the isolation of Fungi were carried out, in different periods of the year, in six environments used as leisure areas by the population, one park and five squares. Among the selection criteria of the sampled environments are the intense flow of people and pets and the presence of organic residues. Of the 43 samples analyzed, $81.4 \%$ were positive for fungal colonies. The occurrence of the identified taxonomic groups of the total of positive samples were: Acremonium sp. (31.25\%), Paecilomyces sp. (20.83\%), Fusarium sp. (14.58\%), Penicillium sp. (8.33\%), Trichoderma sp. (4.14\%), Aspergillus sp. (2.08\%), Epidermophyton sp. (2.08\%), Rhizopus sp. (2.08\%), Sporothrix sp. (2.08\%), Trichophyton sp. (2.08\%). It was concluded that in the soil of the recreational environments studied both dermatophyte and non-dermatophyte fungi occur, with the potential to provoke infections, indicating a low hygienic-sanitary quality and relevant pathogenic potential from the point of view of public health.

Keywords: Mycoses. Dermatophytes. Soil Quality. 


\section{INTRODUÇÃO}

O interesse por temas relacionados à qualidade do solo é relativamente recente, porém, vem se tornando importante e cada vez mais apresentado em discussões sobre a proteção ambiental, da mesma forma que a qualidade do ar e da água (BRADY; WEIL, 2013; BREVIK et al., 2017). Nos últimos anos, devido à incidência de micoses e infecções bacterianas contraídas por crianças que frequentam locais de recreação, tem surgido uma preocupação das autoridades públicas com a contaminação das areias. As areias de praças e parques, assim como as areias de praias, quando expostas a lixo, fezes e urina de animais, secreções do corpo de crianças e adultos se tornam ambientes propícios para a proliferação de bactérias, fungos, vírus e parasitas patogênicos.

Os fungos são seres ubíquos encontrados em associação com animais, incluindo 0 homem, em vegetais, em detritos e no solo, participando ativamente na decomposição de vegetais e reciclagem de elementos vitais (TORTORA; FUNKE; CASE, 2012; WIEDERMANN et al., 2017). O grupo dos fungos denominados de dermatófitos, passíveis de colonizar e causar lesões clínicas em homens e animais, é caracterizado por serem filamentosos, hialinos, septados, algumas vezes artroconidiados, queratinofílicos (ALMEIDA, 2003; PIHET; GOVIC, 2017).

Os dermatófitos são taxonomicamente relacionados e pertencentes à divisão Eumycota, que tem importância médica (LACAZ; PORTO; MARTINS, 1991), subdivisão Deuteromycotina, classe Hyphomycetes, ordem Hyphomycetales, família Moniliaceae e gêneros Microsporum, Epidermophyton e Trichophyton (SIDRIM; ROCHA, 1991). Estes fungos são os agentes causadores da dermatofitose, a qual é considerada a dermatopatia fúngica de maior ocorrência tanto em homens quanto em outros animais, principalmente em cães e gatos (LACAZ; PORTO; MARTINS, 1991).

Os fungos queratinofílicos (dermatófitos e não dermatófitos) são importantes decompositores, produzindo enzimas capazes de degradar queratina e que podem estar presentes nos solos enriquecidos com 
resíduos tegumentares, penas e outros materiais contendo queratina (MARCHISIO, 2000; GUGNANI; SHARMA; WRIGHT, 2014). As espécies pertencentes a esse grupo podem ser encontradas no solo (geofílicos), no homem (antropofílicos) e em animais (zoofílicos) (AQUINO; CONSTANTE; BAKOS, 2000). Dentro destes grupos, estão os dermatófitos que podem causar dermatomicoses no homem e nos animais invadindo tecidos cutâneos superficiais (COSTA et al., 2000; MEDEIROS; CREPALDI; TOGNOLI, 2009).

Esses fungos têm um importante papel ecológico na decomposição de resíduos, desde que eles estejam ecologicamente restritos nesse nicho, degradando queratina como um substrato. Apesar da característica fundamental de decompositor, deve-se

\section{METODOLOGIA}

\section{1 ÁREA DE ESTUDO}

O presente estudo foi conduzido no município de Santarém, que fica na região Oeste do Estado do Pará. No total, foram selecionadas seis áreas de recreação para amostragem de solo, citar também que é cada vez mais frequente a colonização de fungos queratinofílicos dermatófitos e não dermatófitos em homens e animais, causando-lhes infecções oportunistas que, dependendo do estado do hospedeiro, pode se tornar fatal (MARCHISIO, 2000). Diante disso, o estudo da ocorrência desses fungos torna-se cada vez mais importante, principalmente em ambientes em que seres humanos e animais de estimação têm grande contato, tais como praças públicas e parques, que, muitas vezes, são utilizados como áreas de lazer. Nesse sentido, o presente estudo teve o objetivo de verificar a presença de fungos filamentosos queratinofílicos no solo de áreas recreacionais de Santarém, que é um dos municípios mais populosos do Estado do Pará.

sendo cinco praças públicas e um parque (Figura 1). Entre os critérios de seleção dos ambientes amostrados, destacam-se 0 fluxo intenso de pessoas e de animais de estimação e a presença de resíduos orgânicos. 


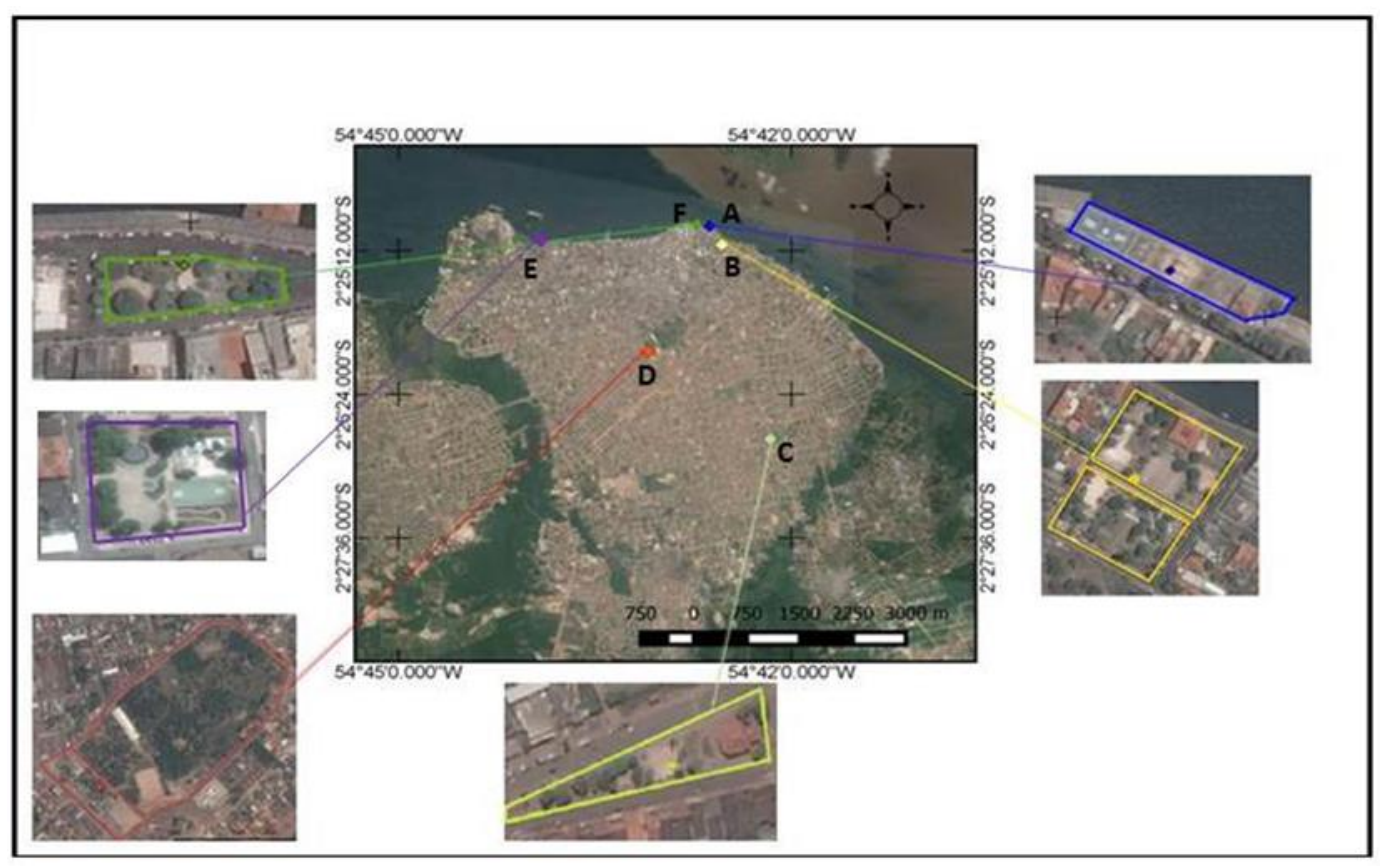

Figura 1 - Localização geográfica dos pontos de coleta de amostras de solo em Santarém - PA. A: Praça do Mascotinho; B: Praça Barão de Santarém; C: Praça da Cohab; D: Parque da Cidade; E: Praça Tiradentes; F: Praça do Pescador.

\subsection{COLETA DE SOLO PARA ANÁLISE MICROBIOLÓGICA}

Duas coletas abrangendo 0 período seco e chuvoso foram realizadas em cada área selecionada para amostragem, conforme descrito na Tabela 1. A primeira coleta ocorreu nos meses de setembro e outubro de 2015, correspondendo ao período seco e a segunda coleta ocorreu nos meses de março e abril 2016, correspondendo ao período chuvoso, totalizando quarenta e três amostras, coletadas do solo, com o auxílio de espátulas estéreis, a dois $\mathrm{cm}$ de profundidade e armazenadas em coletor universal estéreis devidamente identificados.
2.3 ANÁLISES MICROBIOLÓGICAS

Após coleta, as amostras de solo foram encaminhadas ao Laboratório de Ensino Multidisciplinar de Biologia Aplicada (LABIO) da Universidade Federal do Oeste do Pará (UFOPA) e processadas de acordo com a metodologia proposta por Vanbreuseghem (VANBREUSEGHEM, 1952) modificada por Machado (MACHADO, 1977). Cada amostra foi transferida para uma placa de Petri estéril, de $90 \mathrm{~mm}$ de diâmetro, devidamente identificada, onde se adicionou água destilada esterilizada, para umidificar o ambiente e a isca para colonização de fungos queratinofílicos, 
isto é, crina de potro cortada e previamente autoclavada. $O$ tempo esperado para o desenvolvimento dos fungos foi de trinta dias. Após esse período, as amostras com crina nas quais não se observou o crescimento de fungos foram consideradas negativas, enquanto que aquelas onde houve desenvolvimento de colônias foram utilizadas para 0 isolamento desses micro-organismos em Ágar Micobiotic contendo cicloheximida (Himedia).
Após 15 dias de incubação, os espécimes fúngicos foram submetidos ensaio de microcultivo. Após 3 a 5 dias de incubação as lâminas de microcultivo foram analisadas com auxílio de microscópio (Zeiss), com câmera acoplada (AxioCam ERc5s), utilizando-se as objetivas de 10x e 40x para observação das estruturas ou órgãos de reprodução e comparação com literatura apropriada para classificação dos fungos (KERN; BLEVINS, 1999).

Tabela 1 - Amostragem do solo de áreas recreacionais de Santarém - Pará.

\begin{tabular}{ccccccc}
\hline $\begin{array}{c}\text { Período de } \\
\text { amostragem }\end{array}$ & A & B & C & D & E & F \\
\cline { 2 - 6 } & & & & & & \\
\hline $\begin{array}{c}\text { Setembro e } \\
\text { outubro } \\
\text { de } 2015 \\
\text { (período }\end{array}$ & 02 & 04 & 04 & 07 & 01 & 02 \\
seco) & & & & & & \\
\hline $\begin{array}{c}\text { Março e abril } \\
\text { 2016 (período } \\
\text { chuvoso) }\end{array}$ & 02 & 06 & 04 & 07 & - & 02 \\
\hline TOTAL & 04 & 10 & 08 & 14 & 01 & 04 \\
\hline
\end{tabular}

\section{RESULTADOS}

Das amostras de solo analisadas no presente estudo, oriundas de áreas recreacionais, obteve-se $83,72 \%$ de amostras positivas para o crescimento de fungos filamentosos (Tabela 2). 
Tabela 2 - Frequência de amostras positivas e negativas para crescimento de fungos queratinofílicos.

\begin{tabular}{ccc}
\hline CRESCIMENTO & $\begin{array}{c}\text { NÚMERO DE } \\
\text { AMOSTRAS }\end{array}$ & PORCENTAGEM (\%) \\
\hline Positivo & 36 & 83,72 \\
\hline Negativo & 07 & 16,28 \\
\hline TOTAL & 43 & 100 \\
\hline
\end{tabular}

Das 36 amostras positivas, não identificada por meio dos métodos foram cultivadas 48 colônias. Destas, empregados. foram identificados representantes de 10 gêneros de fungos e uma colônia

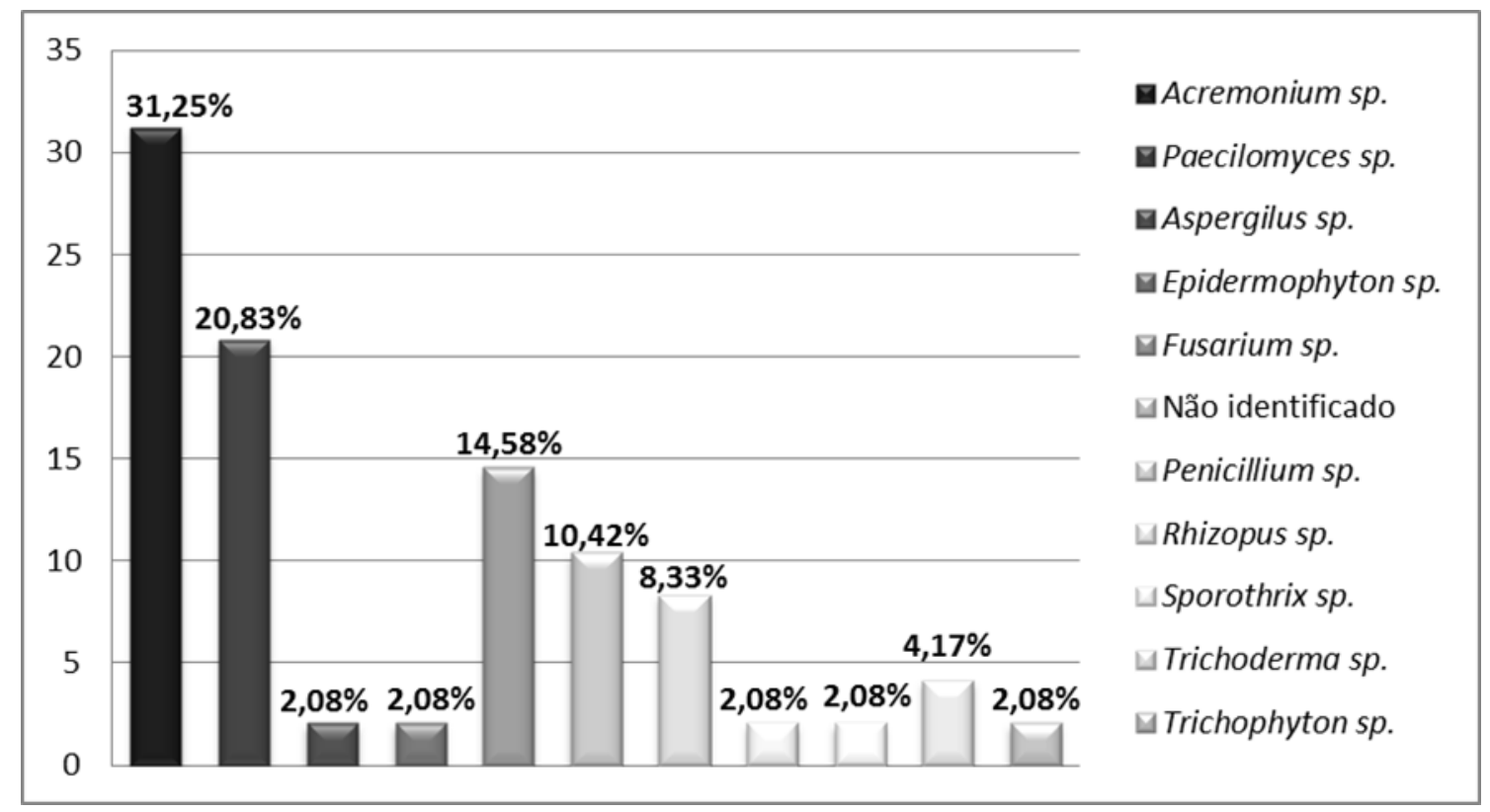

Figura 2 - Positividade de gêneros de fungos queratinofílicos em 43 amostras analisadas.

Entre os grupos taxonômicos de fungos detectados, verificou-se que dois deles compreendem fungos dermatófitos, enquanto que oito compreendem a representantes não dermatófitos, conforme demostrado na Tabela 3. 
Tabela 3 - Quantificação de fungos filamentosos queratinofílicos dermatófitos e não dermatófitos nas colônias estudadas.

\begin{tabular}{ccc}
\hline IDENTIFICAÇÃO & $\begin{array}{c}\text { NÚMERO DE } \\
\text { COLÔNIAS }\end{array}$ & PORCENTAGEM (\%) \\
\hline Dermatófitos & 02 & 4,16 \\
\hline Não Dermatófitos & 41 & 85,42 \\
\hline Não Identificados & 05 & 10,42 \\
\hline
\end{tabular}

\section{DISCUSSÃO}

O número de amostras negativas pode ser explicado por Takahashi et al. (2011), que enfatiza que a maioria dos micro-organismos presentes no solo são não-cultiváveis e, diferentes técnicas tem possibilitado o crescimento satisfatório de microorganismos.

Das 36 amostras positivas, foram cultivadas 48 colônias. Destas, foram identificados representantes de 10 gêneros de fungos e uma colônia não pode ser identificada por meio dos métodos empregados: Acremonium sp. (31,25\%), Paecilomyces sp. (20,83\%), Fusarium sp. (14,58\%), Penicillium sp. (8,33\%), Trichoderma sp. (4,14\%), Aspergillus $\quad \mathrm{sp}$. $\quad(2,08 \%)$, Epidermophyton sp. (2,08\%), Rhizopus sp. $(2,08 \%)$, Sporothrix sp. (2,08\%), Trichophyton sp. (2,08\%) e fungos não identificados $\quad(10,42 \%)$, conforme descrito na Figura 2.
A menor quantidade de fungos dermatófitos encontrada nesta pesquisa também foi discutida em outros trabalhos (TAKAHASHI et al., 2011; ZAMPRONHA et al., 2005). Observou-se que as técnicas utilizadas para o cultivo dos micro-organismos foram limitantes, corroborando com estudos que obtiveram resultados semelhantes de maior positividade de fungos não dermatófitos presentes nas amostras, e também demonstram discussões a respeito do meio de cultivo utilizado para crescimentos dos fungos (TAKAHASHI et al., 2011), pois, - Ágar Micobiotic contendo cicloheximida (Himedia), o qual é um inibidor de fungos não dermatófitos (MACHADO, 1977; ANVISA, 2004), não foi eficaz.

Estudos que apresentam grande positividade de fungos não dermatófitos, ressaltam que métodos mais sensíveis de investigação como 
os que envolvem a biologia molecular, devem ser realizados a fim de corroborar com as análises e para que se possibilite uma noção mais precisa das espécies queratinofílicas causadoras de micoses cutâneas, as quais estariam realmente presentes nos ambientes estudados (TAKAHASHI et al., 2011).

De acordo com os resultados apresentados na Tabela 1, observa-se que do total de positividade $(83,72 \%)$ obteve-se 10 (89.58\%) gêneros diferentes e 1 (10,42\%) grupo de fungos que não foram identificados. As identificações foram feitas com base em características morfológicas das colônias e do microcultivo, mostrando que há uma alta diversidade de fungos filamentosos queratinofílicos dermatófitos e não dermatófitos os quais participam da decomposição da matéria orgânica presente nestes ambientes.

Os gêneros identificados e caracterizados como dermatófitos foram Epidermophyton sp. e Trichophyton sp, que totalizaram $4,16 \%$, conforme listado na Tabela 2 . A maior parte da positividade das amostras analisadas neste estudo foi compreendida por fungos telúricos, ou seja, aqueles que integram a microbiota do solo normalmente. Fungos como estes podem, potencialmente, ocasionar micoses oportunistas em indivíduos imunocomprometidos (GIANI; CERRI; CROSTI, 2000; TAKAHASHI et al., 2011; DEVI; KAUL, 2015).

Os gêneros caracterizados como não dermatófitos foram: Acremonium sp., seguido de Paecilomyces sp., Fusarium sp., Penicillium sp., Trichoderma sp., Aspergillus sp., Rhizopus sp. e Sporthrix sp. Estes achados corroboram com estudos de Bernardi et al. (2009) que também relataram a presença de Aspergillus sp., Penicillium sp., Fusarium sp., Rhizopus sp. e Acremonium sp em solos de praças públicas.

A positividade dos gêneros Aspergillus sp., Fusarium sp., Penicillium sp. e Trichoderma sp. ilustradas na Figura 1, devem ser destacadas pela relação de patogenicidade desses microorganismos a causas de micoses superficiais, ocorrendo em sua grande maioria em pacientes imunocomprometidos (GUGNANI, 2003; WALSH, 2004; SAPNA; ASHISH; KAVITA, 2014). Contudo, a presença de gêneros não dermatófitos revelam a 
diversidade de organismos queratinofílicos, apresentando o potencial patogênico do solo nos ambientes estudados. Pois, sabe-se que tanto os fungos filamentosos queratinofílicos dermatófitos quanto os não dermatófitos podem ser capazes de provocar lesões cutâneas em humanos e outros animais (GUGNANI, 2003).

\section{CONCLUSÃO}

Os resultados dessa pesquisa permitiram concluir que no solo das áreas recreacionais analisadas no município de Santarém - PA ocorrem fungos filamentosos queratinofílicos dermatófitos assim como a presença significativa de gêneros não dermatófitos, ambos de interesse para a saúde pública. Apesar de não ser apresentado, no presente estudo, níveis altos de positividade de fungos caracterizados como dermatófitos nos locais estudados, observou-se uma riqueza relevante de fungos filamentosos não dermatófitos que também participam da degradação da matéria orgânica presente no solo assim como, podem ser responsáveis
Portanto, enfatiza-se que a qualidade ambiental do solo utilizado em áreas de lazer é um importante fator a ser considerado quando se deseja garantir e favorecer a saúde pública, pois este pode ser um veículo de transmissão de diversos microorganismos potencialmente patogênicos, incluindo os fungos (BERNARDI et al., 2009).

por ocasionar infecções oportunistas. Diante do exposto, visualiza-se que estudos incrementais focados em investigações acerca da diversidade, importância ecológica e epidemiológica de fungos nesses ambientes, assim como a possível resistência desses organismos à cicloheximida ou a outros inibidores de crescimento fúngico, devem ser priorizados. Ressalta-se, ainda, a importância de que informações como estas sejam veiculadas e levadas ao conhecimento de governantes e população em geral, para que esses indivíduos sejam capazes de adotar medidas preventivas e de controle da qualidade higiênicosanitária de áreas recreacionais.

\section{REFERÊNCIAS}


ANVISA. Agência Nacional de Vigilância Sanitária. Detecção e Identificação de Fungos de Importância Médica. Brasília. 2004. Mod. VII. 24p.

AQUINO, V.R.; CONSTANTE, C.C.; BAKOS, L. Frequência das dermatofitoses em exames micológicos em Hospital Geral de Porto Alegre, Brasil. An. Bras. Dermatol. v.82, n.3, p. 239-256, 2007.

BERNARDI, A.C.A.; SILVA, J.L.M.; SOUTO, A.P.G.; ALMEIDA, C.C. Estudo de Fungos Queratinofílicos Geofílicos em Praças Públicas de Jaboticabal-SP. Revista Brasileira Multidisciplinar, (Unirana). v. 12, n. 2, p. 79-88, 2015.

BRADY, N. C.; WEIL, R. R. Elementos da natureza e propriedades do solo. 3. ed. Porto Alegre: Bookman, 2013. 716p.

BREVIK, E. C.; STEFFAN, J. J.; BURGESS, L. C.; CERDÀ, A. Links Between Soil Security and the Influence of Soil on Human Health. In: Damien Field, Cristine Morgan, and Alex McBratney (Eds.). Global Soil Security: Progress in Soil Science Series. 1. ed. Rotterdam: Springer, 2017. p. 261-274.

COSTA, M.; PASSOS, X.S.; SOUZA, L.K.H.; MIRANDA, A.T.B.; LEMOS, J.A.; OLIVEIRA JR, J.G.; SILVA, M.R.R. Epidemiologia e etiologia das dermatofitoses em Goiânia, GO, Brasil. Epidemiology and etiology of dermatophytosis in Goiânia, GO, Brazil. Revista da Sociedade Brasileira de Medicina Tropical, v. 35, n. 1, p. 19-22, 2002.

DEVI, A.; KAUL, S. Opportunistic fungal complex as causal organism for skin mycoses in humans. International journal of innovative research \& development, v. 4, n. 10, p. 226-230, 2015.

GIANI, C.; CERRI, A,; CROSTI, C. Non-dermatophytic onychomycosis. An understimated entity? A study of 51 cases. Mycoses, v. 43, p. 29-33, 2000.

GUGNANI, H. C. Nondermatophytic Filamentous Keratinophilic Fungi And Theier Role In Human Infection. Polish Jornal of Envieronmental Studies, v. 12, n. 4, p. 461466, 2003.

GUGNANI, H. C.; SHARMA, S.; WRIGHT, K. A preliminary study on the occurrence of keratinophilic fungi in soils of Jamaica. Revista do Instituto de Medicina Tropical de São Paulo, v. 56, n. 3, p. 231-234, 2014.

KERN, M. E.; BLEVINS, K. S. Micologia Médica: Texto \& Atlas. 2. ed. São Paulo: Premier, 1999. 256p.

LACAZ, C. S.; PORTO, E.; MARTINS, J. E. C. Micologia Médica. 8.ed. São Paulo: Sarvier, 1991. p. 609-615.

MACHADO, O. P. Ocorrência de Dermatófitos em solos no município de GoiâniaGoiás. Revista de Patologia Tropical, v. 6 n. 1,2,3,4., p. 43-67, 1977. 
MARCHISIO, V. Filipello et al. Keratinophilic fungi: their role in nature and degradation of keratinic substrates. Revista Iberoamericana de Micologia. v. 17, p. 86-92, 2000.

MEDEIROS, F.; CREPALDI, N.; TOGNOLI, L. Dermatófitos - Revisão De Literatura. Revista Científica Eletrônica de Medicina Veterinária. Ano VII, n. 12. p. 1-5. 2009.

PIHET, M.; GOVIC, Y. L. Reappraisal of Conventional Diagnosis for Dermatophytes. Mycopathologia, v. 182, p. 169-180, 2017.

SAPNA, R.; ASHISH, S.; KAVITA, S. Study of Keratin Degradation by Some Potential Fungal Isolates from Soil. Indian Journal of Applied Research. v. 4, n. 8, p. 1-3, 2014.

SIDRIM, J.J.C.; ROCHA, M.F.G. Micologia médica à luz dos autores contemporâneos. $1^{\underline{a}}$ ed. Rio de Janeiro: Guanabara Koogan, 2004, 408p.

TAKAHASHI, J. P.; PELEGRINI, A.; PEREIRA, C. Q. M.; SOUZA, M. C. Levantamento de Fungos Queratinofílicos em Solo de Parques e Praças Públicas no Município de São Bernardo do Campo. Revista de Biologia e Ciências da Terra, v. 11, n. 1, p. 4753, 2011.

TORTORA, G. J.; FUNKE, B. R, CASE, C. L. 2012. Microbiologia, 10. ed. Porto Alegre, Artmed.

VANBREUSEGHEM, R. Technique Biologique Pour L’isolement de Dermatophytes du Sol. 1952.

WALSH, T.J.; GROLL, A.; HIEMENZ, J.; FLEMING, R.; ROILIDES, E.; ANAISSIE. Infections Due To Emerging And Uncommon Medically Important Fungal Pathogens. Clinical Microbiology And Infection, v. 10, n. s1, p. 48-66, 2004.

WIEDERMANN, M. M.; KANE, E. S.; POTVIN, L. R.; LILLESKOV, E. A. Interactive plant functional group and water table effects on decomposition and extracellular enzyme activity in Sphagnum peatlands. Soil Biology \& Biochemistry, v. 108, p. 18, 2017.

ZAMPRONHA, V. C. C.; OLIVEIRA, I. P.; MONTEIRO, M. S. R.; SOUZA, H.; SANTOS, K. J. G.; ARAÚJO, A. A. Isolamento e Identificação de Dermatófitos Presentes no Contínuo do Solo de Cerrado do Campus II da Universidade Católica de Goiás. Revista Eletrônica Faculdade Montes Belos, Goiás. v.1, n.1, p.37-49, 2005.

Recebido em: 06/02/2017

Aprovado em: 01/06/2017 